* Advogado. Professor de Direito Empresarial. Coordenador do LLM em Direito Empresarial Aplicado da FIEP. Graduado em Direito pela Universidade Federal do Paraná. Mestrando em Direito das Relações Sociais pela Universidade Federal do Paraná. Autor de diversos artigos acadêmicos. Fluente em inglês, espanhol e francês. E-mail: giovanirralves@uol.com.br ** Mestre em Direito do Estado no programa de pós-graduação em Direito da UFPR. Atualmente é advogado - Felippe, Gomes \& Isfer Advogados e Consultores Associados. E-mail: joseantonio@fgiadvocacia.com.br

\section{Aplicação dos Princípios da Livre Iniciativa e da Legalidade na Interpretação da Organização Associativa}

\author{
Aplication Od THE Free EnTERPRise AND OF \\ Legality Principles In the Interpretation of \\ Associative Organization \\ Giovani Ribeiro Rodrigues Alves * \\ José Antônio Gomes de Araújo **
}

Resumo: Acreditou-se que o Estado de bem estar social seria capaz de tudo prover aos cidadãos, crença que se mostrou distante da realidade fática. Mecanismos tem sido colocados em prática para aperfeiçoamento das relações sociais, incluindo a interação entre Estado e sociedade civil. Esta ligação deve ser vista com cautela, sob risco de impossibilitar a efetivação de direitos e garantias constitucionais basilares, como da livre associação. Há de ser respeitada a liberdade conferida pelo legislador pátrio às associações quanto a sua constituição, organização e desenvolvimento, em prol dos princípios constitucionais e em detrimento de uma indevida interferência estatal.

Palavras-chave: Associações, Terceiro Setor, Desenvolvimento, Histórico Normativo, Regime Supletivo.

Abstract: It was believed that the welfare state would be able to provide everything for all citizens, although this is far from the reality. Mechanisms have been put in place for the continual improvement of social relations, including the interaction between state and civil society. This connection can not be too close, preventing the realization of basic rights and constitutional guarantees such as freedom of association. There is to be respected the freedom conferred by the legislature to the constitution, organization and development of the associations, in favor of constitutional principles and to the detriment of an undue state interference.

Keywords: Associations, Third Sector, Development, Normative History, Default Regime. 


\section{INTRODUÇÃO}

Observa-se do atual contexto político, econômico e social, no qual se encontra o vigente complexo normativo nacional, uma recorrente tentativa de adequação das engrenagens do Estado, que, embora criado para atender o exercício dos direitos sociais e individuais, a liberdade, a segurança, o bemestar, o desenvolvimento, a igualdade e a justiça como valores supremos de uma sociedade fraterna, não vem realizando muitas de suas funções a contento.

Para auxiliar na consecução destes e outros objetivos com maior eficiência, a Lei n.o 9.790, de 1999, a título exemplificativo, inaugurou um novo regramento jurídico para as pessoas jurídicas de direito privado sem fins lucrativos, realizando uma diferenciação das entidades do Terceiro Setor, indicando aquelas com fim público, as quais teriam a possibilidade de receber um credenciamento do Poder Público, denominado Certificado de OSCIP.

O referido diploma normativo buscou promover a aproximação institucional entre a sociedade civil e o Estado, por meio da possibilidade de celebração do Termo de Parceria, pelo qual se possibilitaria a remessa de recursos públicos à entidade qualificada como OSCIP.

Entretanto, nem sempre a união de esforços entre sociedade civil e Estado, a fim de se obter melhores resultados para a coletividade, deve vir precedida de um conjunto normativo ou de uma necessária intervenção estatal direta. Essa observação, de maneira alguma, colide com o consagrado princípio da legalidade, norteador do Direito Público.

Com efeito, há tempos é observado no Brasil a confluência entre os ramos do Direito público e privado, não mais prevalecendo qualquer distinção estática entre os dois, havendo parte da doutrina que sustenta a publicização do Direito Privado e outra a privatização do Direito Público.

Nada obstante, certas limitações devem, necessariamente, ser observadas na interferência entre as esferas público e privada, sob pena de voltarmos a um contexto pré-moderno, marcado pela completa insegurança. Neste sentido, da mesma forma como nos causa repulsa a ideia de particulares fazendo justiça pelas próprias mãos (autotutela), devemos observar a história e temer por uma excessiva ingerência estatal em grupos de pessoas, reunidas para fins pacíficos, como é o caso das associações.

Abordar-se-á no presente artigo o tema associações, a liberdade de organização que a elas deve ser reconhecida e os efeitos dessa liberdade nas associações qualificadas como Organizações da Sociedade Civil de Interesse 
Público. Para tanto, será analisado, inicialmente, o percurso histórico da produção legislativa em matéria de associação no Brasil, com ênfase nas disposições constitucionais e nas disciplinas do Código Civil de 1916 e de 2002.

Em seguida, será examinado o atual panorama normativo das associações, fazendo-se um breve cotejo entre o Código Civil de 2002 e as garantias previstas na Constituição Federal de 1988. Buscar-se-á apresentar a importância do reconhecimento de um amplo espaço de liberdade para os particulares organizarem as suas associações.

Será analisada, logo adiante, a desnecessidade do reconhecimento de um regime jurídico supletivo à normativa das associações, regulada, propositalmente, em pouquíssimos artigos pelo vigente Código Civil. A real efetividade das garantias constitucionais a respeito do tema passa, necessariamente, pelo respeito à autonomia das partes e pela limitação da interferência estatal em seu livre funcionamento e organização.

A seguir, pautados nesta prevalência da autonomia, serão examinadas as disposições que disciplinam as Organizações da Sociedade Civil de Interesse Público e analisada a possibilidade das entidades assim qualificadas, constituídas na forma de associação, contratarem pessoas jurídicas como dirigentes.

Por fim, serão apresentadas as conclusões do trabalho, quanto às regras supletivas que tratam das associações, à dimensão da liberdade de associação de tais entidades e às possíveis formas de contratação dos dirigentes.

\section{BREVE PERCURSO HISTÓRICO DA PRODUÇÃO LEGISLATIVA EM MATÉRIA DE ASSOCIAÇÃO NO BRASIL}

A primeira menção expressa à garantia de livre associação em âmbito constitucional, no Brasil, ocorreu em 1891. Dispunha a Magna Carta brasileira do final do século XIX que "a todos é lícito associarem-se e reunirem-se livremente e sem armas; não podendo intervir a polícia senão para manter a ordem pública" (art. 72, § $8^{\circ}$ ).

Conforme aponta XAVIER LEONARDO (2006, p. 41-42), a primeira constituição republicana trouxe pioneiramente ao Brasil a garantia da liberdade de associação, já que da omissão da Constituição de 1824 a respeito do tema, não era possível presumir a liberdade associativa, em especial por algumas características ainda autoritárias e repressoras do regime de Dom Pedro I, nomeadamente em busca da manutenção da unidade do território brasileiro, 
que resultaram no fato da união de esforços e pessoas ser vista com certo receio por parte do Imperador.

Nada obstante, a partir da primeira Constituição Republicana, o percurso da abordagem da garantia de livre associação por parte das constituições brasileiras foi extremamente linear, ainda que cada uma tenha sido fruto de distintos e, por vezes, contraditórios contextos sociais, políticos e econômicos, que pudessem nos fazer presumir de maneira diferente.

Entretanto, da simples constatação de ter havido a aludida garantia constitucional em momentos extremamente turbulentos e repressores da política brasileira como nos contextos da Constituição de 1937 (Estado Novo), da Constituição de 1967 e da Emenda n 1 de 1969 (Regime Militar), já se constata o fato das previsões constitucionais não terem sido suficientes para que houvesse a efetiva proteção da garantia de livre associação em nosso país.

De nada adiantava a garantia constitucional, se o poder executivo e o poder judiciário se negavam ou se omitiam, respectivamente, a observá-las e as fazer valer, como ocorreu no Brasil em diversos momentos de nossa história. A normatividade da constituição ficava apenas no plano teórico, distante da realidade fática.

Já no âmbito infraconstitucional, limitando-se a análise do presente estudo apenas à matéria codificada, constata-se, primeiramente, que o Código Civil de 1916 não se preocupou nem mesmo em diferenciar sociedades e associações (FERREIRA, 1947, p. 277), o que causou perplexidade na doutrina, já que a Lei $\mathrm{n}^{\circ} 173$ de 1893, muito anteriormente, havia rigorosamente apontado as diferenças entre os dois institutos (XAVIER LEONARDO, 2006, p. 46).

$\mathrm{O}$ atual Código Civil, por sua vez, buscou apresentar elementos distintivos entre sociedade e associação, indicando que enquanto a primeira tem como meio o exercício de atividade econômica com o fim de partilhar o resultado entre os sócios, a segunda tem como principal característica a união de pessoas que se organizam para fins não econômicos.

A despeito de apontar elementos constitutivos das sociedades e associações, pelos quais se pode diferenciar os institutos, o código não chegou a conceituá-los, no que, diga-se de passagem, andou bem, já que a conceituação, via de regra, cabe à doutrina e não ao legislador.

O conceito de associação adotado pelo presente trabalho é o exposto por RIBEIRO e ISFER (2010, p. 79), que afirmam que "a questão que está por definir ou identificar a associação é o propósito com o qual as pessoas se reúnem em torno de uma determinada organização", de modo que a sua existência não 
está ligada à qualidade de seus membros (física ou jurídica), mas à finalidade não econômica buscada pela reunião de pessoas.

A associação tem como principais características, além da consecução de objetivos não-econômicos, a união de pessoas e sua organização com vistas a realizar um objetivo comum, formando uma identidade própria.

A união de pessoas, como característica da associação, deve representar muito mais do que a soma aritmética dos esforços e objetivos de cada associado. Segundo PONTES DE MIRANDA (2002, p. 419) "[n]a liberdade de associação, há mais do que reunião; e o reunir, que lhe é implícito, toma caráter geral, físico e psíquico.”

Na mesma linha, PINTO FERREIRA (1993,p. 139) afirma que a "liberdade de reunião consiste no poder que têm os indivíduos de se aproximarem em grupos a fim de discutir e deliberar", enquanto que "a liberdade de associação consiste numa congregação permanente de pessoas para efeito de conseguir um determinado fim lícito".

Decorrência lógica da reunião entre pessoas é a necessidade de organização das associações, fato que não passou desapercebido pelo legislador pátrio. Identifica-se, pois, das disposições do vigente Código Civil, o estabelecimento de uma estrutura mínima, indispensável a todas as associações, eis que disciplina as regras mínimas necessárias para sua constituição (art. 54, inciso V), desenvolvimento (art. 57, e artigo 59) e dissolução (art. 61), deixando ao alvedrio da própria associação seu detalhamento.

Tais dispositivos devem, necessariamente, ser lidos à luz da Constituição da República, a fim de que não se incorra no mesmo erro do passado de permitir que a legislação infraconstitucional limite direitos e garantias constitucionalmente assegurados.

\section{DAANÁLISE DO DIPLOMA CIVIL À LUZ DA CONSTITUIÇÃO DA REPÚBLICA}

O instituto das associações está assentado no princípio da livre associação, previsto no artigo $5^{\circ}$, inciso XVII da Constituição da República, que dispõe ser "plena a liberdade de associação para fins lícitos, vedada a de caráter paramilitar". O contexto pós-ditadura e os ideais democráticos da Constituição de 1988 nos conduzem a determinada interpretação a respeito do tema.

A Constituição promulgada em 1988 manteve a garantia de liberdade associativa, prevista nas suas antecessoras. Com efeito, previu no art. $5^{\circ}$, incisos 
XVII a XXI, além da (i) garantia a plena liberdade de associação para fins lícitos, (ii) a desnecessidade de autorização, (iii) a vedação à interferência estatal em seu funcionamento e (iv) a garantia de que as associações somente podem ser compulsoriamente dissolvidas ou ter suas atividades suspensas por decisão judicial. Determinou, ainda, que (v) ninguém poderá ser compelido a associarse ou a permanecer associado e, finalmente, previu (vi) a legitimidade representativa das associações, quando expressamente autorizadas.

Em vista dos dispositivos acima sintetizados, JOSÉ AFONSO DA SILVA (2008, p. 267) assevera que a liberdade de associação na vigente Constituição abrange, basicamente, quatro direitos: (1) de criar associação; (2) de aderir a qualquer associação; (3) de desligar-se delas e (4) de dissolvê-las.

Além destes quatro direitos, o autor afirma $(2008$, p. 267$)$ que são aduzidas duas garantias coletivas em favor da liberdade de associar-se: (i) a vedação da interferência estatal no funcionamento das associações e (ii) a impossibilidade de dissolução compulsória ou suspensão das atividades das associações, salvo por decisão judicial, exigindo-se para a primeira o trânsito em julgado da decisão.

Vale destacar, ainda, que são duas as restrições constitucionais expressas à liberdade de associação, quais sejam: (1) que a associação tenha por objeto fim ilícito e (2) que tenha caráter paramilitar. Como afirma o insigne constitucionalista (DA SILVA, 2006, p. 268) "no mais, têm as associações o direito de existir, permanecer, desenvolver-se e expandir-se livremente".

Consoante abordado, verifica-se da história brasileira que a previsão constitucional de garantia de associação não foi suficiente para assegurar o efetivo exercício desta garantia. Se por um lado, há muito tempo, é posição unânime dos juristas a força normativa da Constituição (por todos, ver HESSE, 1991), sob outro vértice é imprescindível que sempre tenhamos em mente a importância de vigiar e fazer valer as garantias constitucionais, em especial no que tange à adequação das leis infraconstitucionais ao teor da Magna Carta.

O constituinte de 1988 buscou assegurar a livre associação, prevendo uma série de garantias e direitos correlatos, elencando pouquíssimas limitações. Dentre as limitações, não se encontram, por exemplo, (1) a impossibilidade da pessoa jurídica fazer parte de associação ou (2) qualquer obrigatoriedade quanto ao modo de organização das associações.

Neste passo, andou bem o Código Civil de 2002 ao não impor limitações extras à livre organização das associações, as quais viriam, certamente, a colidir com as garantias e direitos constitucionalmente previstos quanto ao tema. Como 
AplicaÇão dos Princípios da Livre Iniciativa e da Legalidade na InterpretaÇão da OrganizaÇão Associativa

é cediço, a normativa infraconstitucional deve sempre estar alinhada à Constituição da República.

A organização, elemento essencial ao funcionamento da associação, deve ser interpretada, sempre, à luz da garantia constitucional da liberdade de associação. Em síntese, se a Constituição assegura a liberdade de associação, esta liberdade abrange, igualmente, diversas liberdades correlatas, dentre elas a de sua livre organização.

Disso decorre, portanto, que observados os limites constitucionais, os associados podem se organizar como lhes aprouver, atendidas as parcas limitações, de conteúdo meramente estrutural, regradas entre os artigos 53 a 61 do Código Civil de 2002.

\section{DA LIVRE ORGANIZAÇÃO ASSOCIATIVA E DA DESNECESSIDADE DE UM REGIME SUPLETIVO}

Consequência direta da breve disciplina legal acerca das associações é a recorrente discussão no Brasil relacionada à existência ou, ao menos, à necessidade de ser reconhecido um regime legal supletivo à matéria associativa.

Neste sentido, faz-se, constantemente, analogia ao fato do regime jurídico da sociedade simples ser subsidiário ao das demais sociedades previstas no Código Civil, razão pela qual poderia se considerar que assim seria em relação às associações. Contudo, tal raciocínio não merece prevalecer, por diversos fatores.

Em primeiro lugar, pelo fato de associações e sociedades serem institutos essencialmente distintos, conforme aponta a normativa brasileira desde $1893 \mathrm{e}$ a doutrina há muito mais tempo.

Com efeito, se é possível apontar um norte condutor na existência das sociedades que justifique a possibilidade de um regramento supletivo único, tal não é possível de ser estendido às associações, distintas por sua própria natureza quanto às finalidades.

Em segundo lugar, denota-se da inexistência de previsão legal acerca de um regime subsidiário à disciplina das associações, uma verdadeira opção do legislador, por aquilo que poderíamos chamar de um silêncio eloqüente.

O legislador pátrio buscou preservar e prestigiar a autonomia privada na constituição, organização, desenvolvimento e término das associações. Diferentemente das sociedades, as quais são constituídas essencialmente com a finalidade de obtenção de resultados econômicos, as associações não possuem 
tal objetivo como fator preponderante e, desde que atendidas as limitações e requisitos legais, não merecem maiores preocupações do Estado.

Deste modo, não deve prevalecer qualquer interpretação analógica entre associações e sociedades que conduza à constatação da necessidade ou aplicabilidade de um regime supletivo às normas que regem as associações.

Da mesma forma como é negada pela maior parte da doutrina comercialista a incidência do direito de "desassociação" às sociedades empresárias, em respeito ao princípio da preservação da empresa (por todos, ver RIBEIRO e ISFER 2010, p. 84), deve-se rejeitar a interpretação da existência de um regime supletivo das sociedades simples às associações, sob pena de ser tolhida, indevidamente, garantias e direitos constitucionalmente assegurados.

É possível, portanto, aferir a dimensão da liberdade de organização atribuída às associações, a qual só encontra limites nas parcas disposições estatuídas entre os artigos 53 e 61 do Código Civil, cuja principal função é, em realidade, evitar abusos.

A organização como uma das características principais da associação deve ser interpretada, sempre, à luz da garantia constitucional da liberdade de associação. Disso decorre que os associados podem se organizar como thes aprouver, desde que atendidas as regras básicas dispostas no Código Civil.

Em meio às considerações acima articuladas, é possível afirmar, por exemplo, a possibilidade das associações contratarem pessoas jurídicas como dirigentes, já que não há qualquer preceito que imponha que os dirigentes de associação sejam pessoas naturais.

Com relação a esse tema, aliás, não é possível se pensar em uma interpretação restritiva, mas, sim, ampliativa, reconhecendo-se a existência de tal possibilidade, à luz dos princípios da autonomia privada e da liberdade de associação, constitucionalmente garantidos.

\section{TERCEIRO SETOR E ORGANIZAÇÕES DA SOCIEDADE CIVIL DE INTERESSE PÚBLICO}

Apresentados esses fundamentos e, também, considerando que grande parte das entidades constituídas na forma de associação atuam com objetivo de realizar ações de interesse público, representando importante segmento da sociedade, hoje denominado Terceiro Setor, convém realizar breve exame das disposições que tratam das Organizações da Sociedade Civil de Interesse Público. 
Preliminarmente, vale apontar que ainda que o Terceiro Setor não compreenda apenas as Organizações da Sociedade Civil de Interesse Público, optamos por analisar essa forma de qualificação, por ser a que melhor representa esse segmento, no entendimento dos autores.

Registre-se, inicialmente, que a Lei n.o 9.790, de 1999, inaugurou um novo regramento jurídico às pessoas jurídicas de direito privado sem fins lucrativos. Conforme citado na introdução, realizou uma diferenciação das entidades do Terceiro Setor, indicando aquelas com fim público, que teriam a possibilidade de receber um credenciamento do Poder Público, denominado Certificado de OSCIP.

Promoveu, também, a aproximação institucional entre a sociedade civil e o Estado, permitindo a celebração do Termo de Parceria no qual se possibilitaria a remessa de recursos públicos à entidade.

Em função da possibilidade, atribuída às Organizações da Sociedade Civil de Interesse Público, de obter recursos financeiros do Poder Público, e sua atuação dirigida a consecução de ações de interesse público, seria possível identificar dois critérios que, em conjunto, conferem identidade a essas entidades.

O primeiro deles é o de não ter intuito lucrativo. A leitura dos artigos 1. ${ }^{\circ}$, $2 .^{\circ}$ e $3 .^{\circ}$ da Lei 9.790/99 evidencia essa intenção do legislador. Em outras palavras, o objetivo das entidades qualificadas como OSCIP é similar ao das associações: visam a realização de ações sem intuito lucrativo. O segundo é o que impõe um regime de funcionamento que demonstre a transparência e a sua responsabilização pelos atos que praticar, a teor dos ditames do artigo $4 .^{\circ}$ da Lei 9.790/99.

Nos termos desse preceito legal, a OSCIP está obrigada a cumprir os princípios da administração pública, como os da legalidade, impessoalidade, moralidade, publicidade, economicidade e eficiência (art. $4 .^{\circ}$, inciso I). É obrigada a promover práticas de gestão administrativa que se mostrem transparentes (art. 4. ${ }^{\circ}$, inciso II), dentre as quais se destaca a de constituir conselho fiscal com a atribuição de examinar as contas da entidade (art. $4 .^{\circ}$, inciso III). Nessa mesma linha de entendimento, essas entidades são obrigadas a observar as normas de prestação de contas, destacando a especial necessidade de serem observados os princípios fundamentais da contabilidade (art. $4 .^{\circ}$, inciso VII). Tudo isso com vistas a exigir das OSCIP a plena transparência no funcionamento de tais entidades.

Assim é que, as disposições que disciplinam o funcionamento das OSCIP, impõem regras às associações constituídas como tal, que chegam a derrogar 
parcialmente o princípio constitucional da liberdade de associação. Contudo, assim o fazem com a única finalidade de viabilizar a parceria com o Poder Público, mormente para receberem recursos públicos. Quem não se interessar a firmar parceria com o Poder Público, não está sujeito a tais exigências.

\section{REMUNERAÇÃO DOS DIRIGENTES NAS OSCIP}

A principal das referidas exigências é a que impõe à entidade, a necessidade de não ter fins lucrativos. Para evitar as mais variadas formas de interpretações do que seja uma entidade sem fins lucrativos, o artigo $1 .^{\circ}, \S 1 .^{\circ} \mathrm{da}$ Lei 9.790/99 dispõe que a pessoa jurídica sem fins lucrativos é a que: não distribui, entre os seus sócios ou associados, conselheiros, diretores, empregados ou doadores, eventuais excedentes operacionais, brutos ou líquidos, dividendos, bonificações, participações ou parcelas do seu patrimônio, auferidos, mediante o exercício de suas atividades, e que os aplica integralmente na consecução do respectivo objeto social.

A esse respeito, de plano, cumpre esclarecer que a vedação à "distribuição de excedentes, operacionais, brutos ou líquidos, dividendos, bonificações, participações ou parcelas do seu patrimônio" não atinge o pagamento de remunerações a seus dirigentes e funcionários.

Isto porque, tais pagamentos estão autorizados pelo artigo 4.o, inciso VI da Lei n.o 9.790/99, que permite a remuneração aos dirigentes que trabalham na "gestão executiva e prestam serviços específicos, respeitados, em ambos os casos, os valores praticados pelo mercado, na região correspondente à sua área de atuação". É importante ressaltar que a regra dá cumprimento aos dispositivos constitucionais que enumeram os valores sociais do trabalho, da livre iniciativa e da propriedade privada, garantindo a justa remuneração.

Portanto, pagar a remuneração aos dirigentes, desde que a quantia paga guarde correspondência com a do mercado, não é óbice para se reconhecer o caráter não lucrativo da entidade.

Em disposição similar, a Lei Federal n. ${ }^{\circ}$ 10.101/2002, enumera as peculiaridades das pessoas jurídicas que não podem ser consideradas empresárias.

Ao assim fazer, indica por via reflexa aquelas sem intuito lucrativo, também incluindo nesse rol todas as associações nas quais os associados não recebam participação ou vantagens diretas, dispondo que "não se equipara à empresa, para os fins desta Lei: (...) II - a entidade sem fins 
lucrativos que, cumulativamente: a) não distribua resultados, a qualquer título, ainda que indiretamente, a dirigentes, administradores ou empresas vinculadas; b) aplique integralmente os seus recursos em sua atividade institucional e no País; c) destine o seu patrimônio a entidade congênere ou ao poder público, em caso de encerramento de suas atividades; d) mantenha escrituação contábil capaz de comprovar a observância dos demais requisitos deste inciso, e das normas fiscais, comerciais e de direito econômico que lhe sejam aplicáveis".

Com efeito, o teor do preceito que dispõe sobre a não distribuição de resultado como exigência para que uma pessoa jurídica não seja considerada empresária, é idêntico ao inciso I, artigo 14 do Código Tributário Nacional, requisito indispensável à fruição da imunidade aos impostos sobre patrimônio, renda e serviços das instituições de educação e assistência social, estatuída no artigo 150, inciso VI, alínea "c" da Constituição Federal.

Se ainda é pequena a produção científica acerca do artigo $4 .^{\circ}$, inciso VI da Lei 9.790/99 e do artigo $3 .^{\circ}, \S 2 .^{\circ}$ da Lei n. ${ }^{\circ} 10.101 / 2002$, é pacífico o entendimento dos tributaristas quanto à interpretação do artigo 14, I do Código Tributário Nacional. A lição de Roque Antônio CARRAZZA (2009, p.76) abaixo, explicita com clareza essa posição:

A remuneração dos funcionários e administradores não afasta a imunidade, desde que seja equivalente aos serviços por eles prestados. O que afasta a imunidade é a remuneração exorbitante, que mal consegue esconder a distribuição do patrimônio ou das rendas da entidade.

Como se observa, o artigo 14, I do Código Tributário Nacional e o artigo 4. ${ }^{\circ}$, inciso VI, da Lei 9.790/99, disciplinam exatamente o mesmo tema: tanto para a fruição da imunidade tributária, como para a qualificação de entidade como OSCIP junto ao Ministério da Justiça, é autorizada a remuneração dos dirigentes.

Há de se considerar, como ressalva, que esse dispositivo (art. $4 .^{\circ}$, inciso VI) não fixa critérios claros que possam estabelecer com o rigor necessário o teto da remuneração. $\mathrm{O}$ único limite é o das remunerações pagas com os recursos financeiros do Termo de Parceria. Nesse caso, de acordo com o artigo 10, § 2.o, inciso IV da Lei n.o 9.790/99, os pagamentos devem constar do Termo de Parceria, o que impõe um controle mais rigoroso (DINIZ, 2003, p.28).

O que não pode acontecer é a distribuição de dividendos, de parte do patrimônio ou do resultado, situação bastante distinta da simples remuneração paga ao dirigente. 


\section{DA MODALIDADE DE CONTRATAÇÃO NAS OSCIP}

Ao tratar do vocábulo remuneração, o artigo 4. ${ }^{\circ}$, inciso VI da Lei 9.790/ 99 autoriza o pagamento de contraprestação financeira aos dirigentes que atuam na gestão executiva e àqueles que prestam serviços específicos.

Mas a palavra "remuneração" não está relacionada a uma modalidade específica de contratação de serviços. DE PLÁCIDO E SILVA (1982, p.91) a define como "denominação genérica da quantia que se paga pela locação de coisas ou de serviços. Compreende o aluguel ou renda, o salário, a soldada, o ordenado, os honorários, o preço".

Essa generalidade que se extrai do significado do vocábulo remuneração, se confirma após a análise da natureza das duas espécies de trabalho referidas no preceptivo legal. Fala-se em gestão executiva e atividade específica. A gestão executiva compreende a atuação da pessoa que conduz as atividades de consecução dos objetivos sociais da entidade. Já a prestação de serviços específicos, por outro lado, compreende a atividade técnica ou especializada.

Nesta esteira, Paes $\left(1999\right.$, p.103) esclarece que o artigo $4 .^{\circ}$, inciso VI da Lei 9.790/99, passou a autorizar a remuneração dos dirigentes das entidades sem fins lucrativos, tanto na condição de executivos, como na condição de profissionais liberais, consultores e empregados administrativos.

A natureza dessas duas espécies de trabalho (gestão executiva e atividade específica), como se vê, não impõe uma modalidade específica de contratação ou uma forma específica de atuação. Da mesma maneira, não aponta para a necessidade exclusiva de contratação de pessoas naturais.

Nesse particular, aliás, estaria alinhado ao interesse público a eventual decisão das entidades do Terceiro Setor, que promovesse a contratação de pessoas jurídicas para essas funções, pois reduziria em muito as despesas da entidade com carga tributária.

\section{CONCLUSÃO}

Dos fundamentos acima explicitados, é possível concluir que em se tratando de associação, os direitos e garantias constitucionalmente assegurados devem ser atentamente vigiados pelos cidadãos, sob pena de entrarmos em uma nova era de desrespeito total aos ditames da Carta Magna, como já ocorreu em passado recente. 
Para além das limitações expressamente contidas na Constituição Federal, não se pode criar, a que título for, restrições aos direitos direta e indiretamente derivados do princípio da livre associação. Com efeito, a liberdade das associações se organizarem como lhe aprouverem é decorrente da própria Constituição, vedados, obviamente, abusos de direito.

Tanto o princípio da legalidade, consagrado no artigo $5^{\circ}$, inciso II da Constituição Federal, quanto a falta de previsão no ordenamento jurídico vigente, conduzem à interpretação da inexistência de um regime legal que regulamente em caráter supletivo as associações. Interpretação em contrário levaria ao indevido reconhecimento de limitações extras a garantias constitucionalmente asseguradas.

Disto decorre a conclusão, por exemplo, de que não há como se sustentar que as associações, por meio de uma interpretação analógica de outros regramentos, estejam proibidas de contratar pessoas jurídicas como dirigentes. No mesmo sentido, em relação às associações qualificadas como OSCIP, não há na Lei 9.790/99 ou em qualquer outro diploma legal que trate das Organizações da Sociedade Civil de Interesse Público, disposição que imponha que seus dirigentes sejam pessoas naturais e não jurídicas.

Ademais, lembre-se que no que tange às limitações extras decorrentes de leis que regulamentem parcerias entre o Poder Público e associações devem ser vistas como simples decorrência da remessa de recursos públicos para as entidades, não se podendo, de forma alguma, ampliá-las para entes associativos que não tenham a mesma pretensão de parceria direta com o ente estatal.

\section{REFERÊNCIAS}

CARRAZZA, Roque Antonio. Curso de direito constitucional tributário. 25.ed. rev., amp. e atual. São Paulo: Malheiros, 2009.

DINIZ, Gustavo Saad. Direito das fundações privadas. teoria geral e exercício de atividades econômicas. 2.ed. Porto Alegre: Síntese, 2003.

FERREIRA, Pinto. Curso de direito constitucional. 6. Ed. São Paulo: Saraiva, 1993.

FRANCO, Augusto de. Prefácio à primeira edição: o que está por trás da nova lei do terceiro setor. In: FERRAREZI, Elisabete; REZENDA, Valéria. 
OSCIP: organização da sociedade civil de interesse público: a lei 9.790/99 como alternativa para o terceiro setor. Disponível em:

<www.comunidadesolidaria.org.br>. Acesso em: 19 fev. 2012.

HESSE, Konrad. A Força Normativa da Constituição. Tradução de Gilmar Ferreira Mendes. Porto Alegre: Sérgio Antônio Fabris Editor, 1991.

LEONARDO, Rodrigo Xavier. As Associações em Sentido Estrito no Direito Privado. Tese de Doutorado disponível em http:// www.losso.com.br/portal/biblioteca/41.pdf. São Paulo: Faculdade de Direito de São Paulo, 2006.

MIRANDA, Pontes de. Democracia liberdade igualdade (os três caminhos). São Paulo: Bookseller, 2002.

PAES, José Eduardo Sabo. Fundações e entidade de interesse social: aspectos jurídicos, administrativos, contábeis e tributários. Brasília: Brasília Jurídica, 1999.

RIBEIRO, Marcia Carla Pereira; ISFER, Edson. Direito de (des)associação e o princípio da manutenção da empresa. Revista de Direito Mercantil Industrial, Econômico e Financeiro, v. 151/2, p.79-89, 2010.

SILVA, José Afonso da. Curso de Direito Constitucional Positivo. São Paulo: Malheiros, $31^{\text {a }}$ edição, revista e atualizada, 2008.

SILVA, De Plácido e. Vocabulário Jurídico. 7.ed. Rio de Janeiro: Forense, 1982.

Recebido em: 13/08/2012 Aprovado para publicação em: 16/04/2013

Como citar: ALVES, Giovani Ribeiro Rodrigues; ARAÚJO, José Antônio Gomes de. Aplicação dos Princípios da Livre Iniciativa e da Legalidade na Interpretação da Organização Associativa. Revista do Direito Público, Londrina, v.8, n.1, p.53-66, jan./abr.2013. DOI: 10.5433/1980-511X.2013v8n1p53. 